\title{
Financial stress and income disparities in parents of children with special health care needs
}

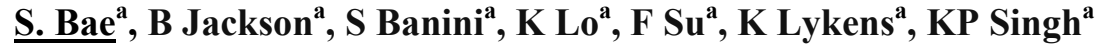 \\ ${ }^{a}$ Department of Biostatistics, University of North Texas Health Science Center School of Public Health; Fort \\ Worth, Texas \\ Email: sejong.bae@unthsc.edu
}

\begin{abstract}
Children with special health care needs (CSHCN) generally use more health care and related services than do typically developing children, which increases the financial burden placed on the parents. The aim of this study is to use nationally representative data to explore the factors of financial stress across income levels of CSHCN. For this study the variables utilized were chosen from the stressors, resources, and support components. Multiple logistic regression was used to analyze the relationship between financial stress and the covariates of interest. We found that in all income categories, having a child with autism increased the odds of having financial stress. Our results suggest that the identified factors of financial stress differ according to the income of the families of CSHCN. Changes to health care systems and public policy particularly eligibility rules and benefit packages can potentially help reduce stress and decrease the number of CSHCN.
\end{abstract}

Keywords: Children with special health care needs (CSNCN), financial stress, disparity 
Bae et al., Financial stress and income disparities in parents of children with special health care needs

\section{INTRODUCTION}

Parenting children with developmental disorders may be a significant source of stress. The level of parenting stress is greater in parents of children with developmental problems compared to parents of normally developing children (Dabrowska and Pisula, 2010). Having high levels of parenting stress can result in harsh or withdrawn parenting with consequences for child development (DeaterDeckard , 2004). Raising a child with a developmental disorder increases the risk of distress in parents and other direct family members. Children with special health care needs (CSHCN) generally use more health care and related services than do typically developing children, which increases the financial burden placed on the parents (Newacheck and Kim, 2005). Lack of financial resources for a CSHCN can have a large impact on work and the family's functioning ability, leading to elevated levels of stress.

Several authors suggest that autism in children presents the greatest threat to the psychosocial well being of parents. The impact of an autistic child on the family economy is presumably large. Families with autistic children spend more in health care services than other families. A recent study of nationally representative samples from the Medical Expenditure Panel and the National Hospital Ambulatory Medical Care Survey estimated that parents of children with autism spectrum disorders spend \$5,272 more in health care services than other families (Liptak et al., 2006).

The stress experienced by parents of children with autism depends on various factors. It has been found that a mother's experienced stress is related to the child's characteristics and ability to socialize with others (Baker-Ericzen et al., 2005). Fathers appear to be more affected by other life stressors such as employment and the family's financial standing as well as the child's communication problems as well (Dabrowska and Pisula, 2010).

Previous literature of children with autism had focused on the parent's effects on the child, more recently there has been a shift to an examination of the how the child affects the parents (Marshall and Long, 2010). Studies suggest that having a child with autism has a negative impact on paternal psychological functioning, previous work has been performed in clinical settings or small samples, this supports the need for further investigation into large scale population based analyses (Montes and Halterman, 2007). The aim of this study is to use nationally representative data to explore the factors of financial stress across income levels of CSHCN.

\section{METHODS}

According to Adrienne Perry's theoretical model of stress in families of children with developmental disabilities, there are four components in the process of stress: Stressors, Resources, Support, and Outcomes (Perry, 2004). Stressors include child characteristics (child's age, gender, type of disorder) and other life stressors (illness in other family members, costs of treatment). Resources include an individual's personal resources (education and coping), and family system resources (marital status, family structure, and socio-economic status). Supports include formal (professional counseling and respite care) and informal (extended family or neighbors) sources, and Outcomes can either be positive or negative. Perry's model has been validated for studies involving stress for developmental diseases (Wulffaert et al., 2009; Perry et al. 2004). For this study the variables utilized were chosen from the stressors, resources, and support components.

\subsection{Dataset}

The data utilized in this study came from the National Survey of Children with Special Health Care Needs (NS-CSHCN). The survey collected data between April 2005 and February of 2007, and explored the extent to which CSHCN have medical homes, adequate health insurance, and access to needed services. Other topics include functional difficulties, care coordination, satisfaction with care, and transition services. Interviews were conducted with the parent or guardian who know 
about the child's health. The Interview, Screener, and Household datasets were sorted and merged by two unique identifiers to create a single dataset. The dataset comprised of children less than 18 years of age. More than 3,000 households with children were screened to identify $750 \mathrm{CSHCN}$ in each state and DC. A national referent sample of approximately 5,000 children without special health care needs was also selected, so that characteristics may be compared with CSHCN. There were 40,840 completed special needs interviews (www.cdc.gov/nchs/data/series/sr_01/sr01_045.pdf, Accessed 27 May, 2010).

\subsection{Financial stress definition}

The dichotomous variable 'financial stress' was derived from these questions: whether the child's health care has caused financial problems, whether family members have cut work hours to care for child, whether the respondent needed additional income for child's medical expenses, and whether Family member stopped working due to child's health condition (Montes and Halterman, 2007; Montes and Halterman, 2008). Subjects who gave at least one affirmative answer to these questions were classified as having financial stress.

\subsection{Variable definitions}

The variables selected corresponding to Stressors were child's gender, race/ethnicity, relationship to the child (mother or not-mother), and primary household language. The variables selected for the resources component were: the household's highest level of education, type of insurance, and income level based on the relative position to the Federal Poverty Level (FPL). Income level was divided into three categories: Less than or equal to 200\% FPL, 201-300\% FPL, and higher than $300 \%$ FPL. Families in the lowest income category are primarily served by public programs and insurers, and families in the highest income category are predominantly served through private insurers and providers.

For Support variables we looked into whether or not the family stated the need in the previous 12 months for respite care. Respite care (temporary care of a few hours or weeks to provide relief to family members who usually care the children) has been identified as key support for families with children with autism (Preece and Jordan, 2007). Reduced stress has been observed in families where respite care has been available, and provides the means for taking care of children as well as providing siblings of children with methods of taking care of the CSHCN.

\section{STATISTICAL ANALYSIS}

Descriptive statistics are provided for age of child, gender of child, race of child (White, Black/African-American, Hispanics, Others), Relation to child (mother, others), Family structure (Two parents-biological/adopted, Two parents-step family, Single mother, others), Primary household language (English, Spanish), paternal education (less than high school, high school graduate, more than high school), insurance type (private, public, private and public, others, uninsured), child's autistic status, need for respite care. Multiple logistic regression was used to analyze the relationship between financial stress and the covariates of interest. Analysis was performed with SAS v9.1.3 using PROC SURVEYLOGISTIC with the appropriate survey parameters to account for the complex survey design and adjusted odds of having financial stress were examined according to income level.

\section{RESULTS}

In our study there were 40,723 children with special health care needs from the NS-CSHCN, 2006. Among the study population, $5.4 \%$ of the children had autism, $35.76 \%$ had attention deficit disorder (ADD) or mental retardation (data not shown), and 59.36\% were male. A majority of the respondents were mothers $(79.60 \%)$, and a majority had more than a high school education $(70.08 \%)$. With regard to the family's income level, the sample consisted of $30.65 \%$ in the lowest 
Bae et al., Financial stress and income disparities in parents of children with special health care needs

group (less than 200\% FPL), 26.31\% in the middle group (between 200 and 300\% FPL), and $43.04 \%$ in the upper group (greater than $300 \%$ FPL).

Table 1 presents the unweighted frequency and weighted percentages of having financial stress for the independent variables stratified by income level. The percentage of parents of autistic children who are experiencing financial stress is similar across income levels. For parents of children without autism, there is a decrease in the percentage that experience financial stress as income level increases. Financial stress levels are similar regardless of the age category of the child within each income level, as income level increases the weighted percentages of parents experiencing financial stress decreases. In terms of the child's gender, the percentage of parents experiencing financial stress was greatest for those with a male child across all income groups. Hispanic families have the highest percentage of financial stress in the low and middle income categories. A greater

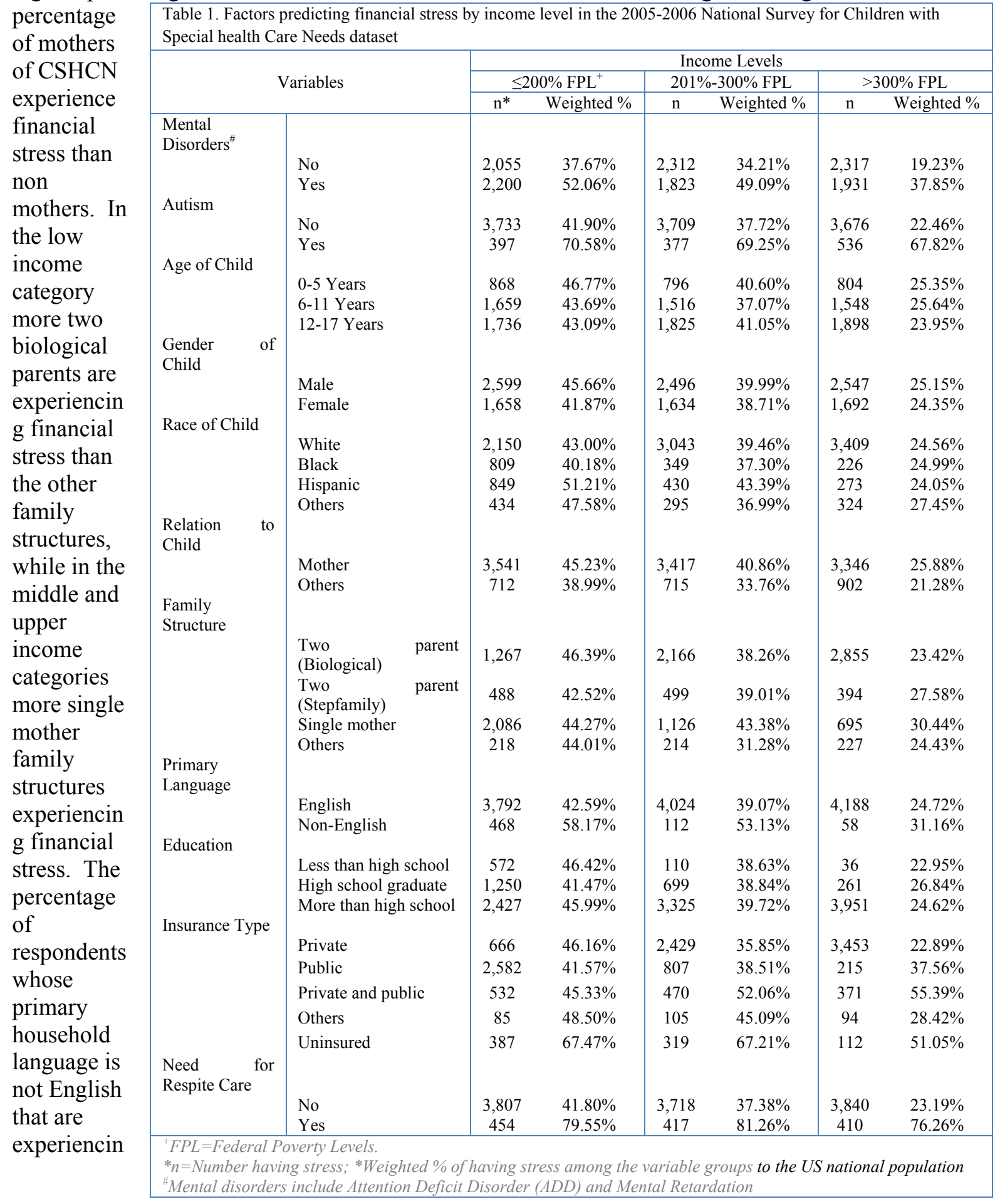


Bae et al., Financial stress and income disparities in parents of children with special health care needs

$\mathrm{g}$ financial stress is consistently higher then English speakers in all income categories. As income level increases the percentage of respondents who experience financial stress decreases for those who are privately insured and those who are publically insured, however for those who are uninsured or have a combination of public and private insurance, the percentage of respondents experiencing financial stress increases. In the low and middle income group, the percentage of parents experiencing financial stress who reported having a need for respite care in the past 12 months is similar, whereas in the highest income group the percentage experiencing financial stress is higher.

Multiple logistic regression was performed, and from our observation of differing levels of

\begin{tabular}{|c|c|c|c|c|c|c|c|}
\hline & \multirow{3}{*}{ Variables } & \multicolumn{6}{|c|}{ Income Levels } \\
\hline & & \multicolumn{2}{|c|}{$\leq 200 \% \mathrm{FPL}^{\#}$} & \multicolumn{2}{|c|}{$201 \%-300 \%$ FPL } & \multicolumn{2}{|c|}{$>300 \% \mathrm{FPL}$} \\
\hline & & $\mathrm{AOR}^{*}$ & $95 \% \mathrm{CI}$ & $\mathrm{AOR}$ & $95 \% \mathrm{CI}$ & AOR & $95 \% \mathrm{CI}$ \\
\hline \multirow[t]{3}{*}{ Autism } & & & & & & & \\
\hline & No & - & - & - & - & - & - \\
\hline & Yes & 2.93 & $(2.13,4.01)$ & 3.03 & $(2.13,4.31)$ & 5.87 & $(4.53,7.59)$ \\
\hline \multirow{4}{*}{$\begin{array}{l}\text { Age of } \\
\text { Child }\end{array}$} & & & & & & & \\
\hline & $0-5$ Years & 1.11 & $(0.91,1.35)$ & 1.05 & $(0.85,1.29)$ & 1.04 & $(0.88,1.22)$ \\
\hline & 6-11 Years & 1.01 & $(0.86,1.19)$ & 0.86 & $(0.73,1.01)$ & 1.07 & $(0.93,1.23)$ \\
\hline & 12-17 Years & - & - & - & - & - & - \\
\hline \multirow[t]{3}{*}{$\begin{array}{l}\text { Gender of } \\
\text { Child }\end{array}$} & & & & & & & \\
\hline & Male & - & - & - & - & - & - \\
\hline & Female & 0.96 & $(0.83,1.11)$ & 1.02 & $(0.88,1.18)$ & 1.08 & $(0.95,1.23)$ \\
\hline \multirow[t]{5}{*}{$\begin{array}{l}\text { Race of } \\
\text { Child }\end{array}$} & & & & & & & \\
\hline & White & - & - & - & - & - & - \\
\hline & Black & 0.91 & $(0.76,1.09)$ & 0.85 & $(0.65,1.11)$ & 0.91 & $(0.70,1.18)$ \\
\hline & Hispanic & 1.04 & $(0.81,1.34)$ & 0.98 & $(0.74,1.30)$ & 0.93 & $(0.71,1.23)$ \\
\hline & Others & 1.22 & $(0.95,1.57)$ & 0.81 & $(0.58,1.12)$ & 1.11 & $(0.87,1.41)$ \\
\hline \multirow[t]{3}{*}{$\begin{array}{l}\text { Relation } \\
\text { to Child }\end{array}$} & & & & & & & \\
\hline & Mother & 1.36 & $(1.05,1.76)$ & 1.38 & $(1.12,1.70)$ & 1.30 & $(1.10,1.53)$ \\
\hline & Others & - & - & - & - & - & - \\
\hline \multirow{5}{*}{$\begin{array}{l}\text { Family } \\
\text { Structure }\end{array}$} & & & & & & & \\
\hline & $\begin{array}{l}\text { Two parent } \\
\text { (Biological) }\end{array}$ & - & - & - & - & - & - \\
\hline & $\begin{array}{l}\text { Two parent } \\
\text { (Stepfamily) }\end{array}$ & 0.95 & $(0.73,1.23)$ & 1.08 & $(0.86,1.36)$ & 1.27 & $(1.01,1.59)$ \\
\hline & Single mother & 0.93 & $(0.79,1.1)$ & 1.22 & $(1.02,1.46)$ & 1.31 & $(1.10,1.56)$ \\
\hline & Others & 1.10 & $(0.72,1.68)$ & 0.76 & $(0.52,1.10)$ & 1.01 & $(0.75,1.37)$ \\
\hline \multirow{3}{*}{$\begin{array}{l}\text { Primary } \\
\text { Language }\end{array}$} & & & & & & & \\
\hline & English & 0.62 & $(0.45,0.87)$ & 0.61 & $(0.36,1.02)$ & 0.80 & $(0.48,1.31)$ \\
\hline & Non-English & - & - & - & - & - & - \\
\hline \multirow{3}{*}{ Education } & $\begin{array}{l}\text { Less than high } \\
\text { school }\end{array}$ & 0.88 & $(0.75,1.02)$ & 0.99 & $(0.83,1.18)$ & 1.10 & $(0.87,1.39)$ \\
\hline & $\begin{array}{l}\text { High school } \\
\text { graduate }\end{array}$ & 1.05 & $(0.84,1.32)$ & 0.92 & $(0.58,1.44)$ & 0.81 & $(0.41,1.61)$ \\
\hline & $\begin{array}{l}\text { More than high } \\
\text { school }\end{array}$ & - & - & - & - & - & - \\
\hline \multirow[t]{6}{*}{$\begin{array}{l}\text { Insurance } \\
\text { Type }\end{array}$} & & & & & & & \\
\hline & Private & - & - & - & - & - & - \\
\hline & Public & 0.77 & $(0.63,0.94)$ & 1.03 & $(0.84,1.26)$ & 1.64 & $(1.10,2.45)$ \\
\hline & Private and public & 0.88 & $(0.67,1.16)$ & 1.53 & $(1.17,2.00)$ & 2.86 & $(2.11,3.88)$ \\
\hline & Others & 1.01 & $(0.56,1.82)$ & 1.50 & $(0.95,2.39)$ & 1.23 & $(0.66,2.31)$ \\
\hline & Uninsured & 2.15 & $(1.52,3.04)$ & 3.62 & $(2.61,5.02)$ & 3.24 & $(2.12,4.94)$ \\
\hline \multirow[t]{3}{*}{$\begin{array}{l}\text { Need for } \\
\text { Respite } \\
\text { Care }\end{array}$} & & & & & & & \\
\hline & No & - & - & - & - & - & - \\
\hline & Yes & 4.65 & $(3.26,6.62)$ & 6.71 & $(4.52,9.96)$ & 5.75 & $(3.46,9.54)$ \\
\hline
\end{tabular}
financial stress according to income level, we tested for interaction and found significant interaction $(p<0.001)$ between autism and income level. We stratified our regressions by income level and included all predicting factors in the models. The adjusted odds ratios and their $95 \%$ confidence intervals of experiencing financial stress stratified by income level are seen in table2. Autism is a significant factor $(p<0.001)$ across all income levels. Adjusting for the other covariates, the odds of experiencing financial stress in parents of children with autism compared to parents without autistic children increases with income level (adj. OR by increasing income strata $=2.93,3.03,5.87$ ). The 
respondent's relationship to the child is also a significant factor across all income levels, compared to non-mothers, there is at least a 30\% increase in mother's odds of experiencing financial stress across income levels (adj. OR by increasing income strata $=1.36,1.38,1.30$ ). The type of family structure has a significant effect on the odds of experiencing financial stress only in the highest income category. Compared to the two biological or adopted parents, the two parent stepfamily has a $27 \%$ increase in odds, and the single mother/no father family structure has a $31 \%$ increase in odds of experiencing financial stress. Primary language is a significant $(\mathrm{p}=0.006)$ factor in the low income group. For respondents in the low income group, those whose primary language is English have a 38\% reduction in odds of experiencing financial stress compared to respondents whose primary language is not English. The need for respite care was a significant factor across all income levels $(\mathrm{p}<0.001)$. Compared to respondents who did not need respite care in the previous 12 months, respondents who reported a need for this service had 4.65 times the odds of experiencing financial stress in the low income category, 6.71 times the odds in the middle income category and 5.75 times the odds in the highest income category. The type of insurance is a significant factor, where across all income levels the uninsured respondents experience more financial stress.

\section{DISCUSSION}

In this study it is observed that having a child with autism greatly increases the odds of the parent's financial stress. This coincides with other studies implications that autism poses a larger threat to the psychosocial well being of parents than other disorders (Gray, 2006). In our study we found that in all income categories, having a child with autism increased the odds of having financial stress. In all income categories there were a greater percentage of respondents who experienced stress from having a child with autism compared to having a child with Attention Deficit Disorder or Mental retardation (data not shown).

Reports on the stress experiences of parents of children with developmental disorders are mixed. Some studies suggest that the stress experienced by mothers is linked with the child's characteristics and social functioning skills, and that a father's stress is linked with financial concerns and job status, while other studies suggest that both parents feel similarly about their child's social ability and personality (Ricci and Hodapp, 2003). Our definition of financial stress shows that mothers are more likely to experience financial stress than non mothers, which in concert with previous studies supports the notion that both mothers and fathers are affected both by the child's characteristics and financial/job concerns. It was observed that in the lowest income category the largest percentage of mothers reported experiencing financial stress.

Providing long term care can elicit financial and family stress which can result in decreased quality of care and neglect, the use of respite care has demonstrated a reduction in caregiver stress (Conlin et al., 1992). With respect to the need for respite care in the previous 12 months, the current analysis revealed that the middle income category had the highest percentage of parents experiencing stress. Low and high income families may have some social support such as respite care covered in their insurance plan, while the middle income families may not be able to qualify for public insurance coverage and may not afford the out of pocket costs of social support services. Insurance coverage for CSHCN differs between each state, while some states have passed autism specific insurance mandates; very few states have specifically mandated coverage for structured behavioral therapy. At a community level restrictive Medicaid/SCHIP eligibility requirements, and low health care provider to population ratio are barriers for families of CSHCN Personal care through the Title XIX Medicaid program have enabled some families to receive respite care for free or at a reduced cost (http://www.archrespite.org/archfs4.htm\#Resources, Accessed 08 June, 2010). 
Bae et al., Financial stress and income disparities in parents of children with special health care needs

\section{CONCLUSION}

Our results suggest that the identified factors of financial stress differ according to the income of the families of CSHCN. Depending on the income of the family, different factors modify the effects on financial stress. While additional formal support services such as respite care can alleviate the stress experienced, policy makers and practitioners should improve the availability and access to care for middle income families of CSHCN. Changes to health care systems and public policy particularly eligibility rules and benefit packages can potentially help reduce stress and decrease the number of CSHCN. This research has implications for the design and implementation of support programs for parents of CSHCN that can be arranged for families in different income categories to help reduce financial stress.

\section{REFERENCES}

Dabrowska A, Pisula E. (2010) Parenting stress and coping styles in mothers and fathers of preschool children with autism and down syndrome. J Intellect Disabil Res. 54(3),266-280.

Deater-Deckard K. ( 2004) Parenting Stress. New Haven, CT: Yale University Press.

Newacheck PW, Kim SE. (2005) A national profile of health care utilization and expenditures for children with special health care needs. Arch Pediatr Adolesc Med. 159(1),10-17.

Liptak GS, Stuart T, Auinger P. (2006) Health care utilization and expenditures for children with autism: Data from U.S. national samples. J Autism Dev Disord. 36(7),871-879.

Baker-Ericzen M.J., Brookman-Frazee L., Stahmer L. (2005) Stress levels and adaptability in parents of toddlers with and without autism spectrum disorders. RPSD. 30,194-204.

Marshall V, Long BC. (2010) Coping processes as revealed in the stories of mothers of children with autism. Qual Health Res. 20(1), 105-116.

Montes G, Halterman JS. (2007) Psychological functioning and coping among mothers of children with autism: A population-based study. Pediatrics. 119(5), e1040-6.

Perry A. (2004) A model of stress in families of children with developmental disabilities: Clinical and research applications. JDD. 11,1-16.

Wulffaert J, Scholte EM, Dijkxhoorn YM, Bergman JE, van Ravenswaaij-Arts CM, van Berckelaer-Onnes IA. (2009) Parenting stress in CHARGE syndrome and the relationship with child characteristics. J Dev Phys Disabil. 21(4):301-313.

Perry A, Harris K, Minnes P. (2004) Family environments and family harmony: An exploration across severity, age, and type of DD. JDD. 11,17-30.

Blumberg SJ, Welch EM, Chowdhury SR, et al. Design and operation of the national survey of children with special health care needs, 2005-2006. Available at: www.cdc.gov/nchs/data/series/sr 01/sr01 045.pdf. Accessed 05/27, 2010.

Montes G, Halterman JS (2008) Association of childhood autism spectrum disorders and loss of family income. Pediatrics. 121(4), e821-6.

Preece D, Jordan R. (2007) Short breaks services for children with autistic spectrum disorders: Factors associated with service use and non-use. J Autism Dev Disord. 37(2),374-385.

Gray DE. (2006) Coping over time: The parents of children with autism. $J$ Intellect Disabil Res. 50(Pt 12),970-976.

Ricci LA, Hodapp RM. (2003) Fathers of children with down's syndrome versus other types of intellectual disability: Perceptions, stress and involvement. J Intellect Disabil Res. 47(Pt 4-5), 273-284

Conlin MM, Caranasos GJ, Davidson RA. (1992) Reduction of caregiver stress by respite care: A pilot study. South Med J. 85(11),1096-1100

ARCH National Respite Network. Respite care for children with developmental and/or physical disabilities: A parent's perspective. Available at: http://www.archrespite.org/archfs4.htm\#Resources. Accessed 06/08, 2010. 